\title{
The implications of doctoral mobility for doctoral programme design and supervision
}

\author{
Rebekah Smith McGloin, Nottingham Trent University
}

\section{Introduction and overview}

This chapter explores the trends and flows in academic mobility, the policy imperatives that drive it and the personal experiences of doctoral researchers who undertake it. We use the findings of a 2018 survey of UK doctoral researchers to examine the endogenous and exogenous enablers and constraints to doctoral mobility, and we explore the value of mobility to the respondents in terms of career development and knowledge development. The chapter concludes with some thoughts on how the policy discourse around international mobility and the individual experience thereof intersect and how funders, higher education institutions, graduate schools or doctoral colleges and supervisory teams might mitigate the challenges and risk identified and amplify the positive impacts in order to better support the doctoral community.

Against a backdrop of anti-globalisation in many parts of the world ${ }^{1}$ - with ethno-nationalist and antiimmigrant sentiments popular amongst supporters of Trump and Brexit, the rise of polarising and controversial figures in leadership positions in Brazil and Italy, and anti-immigrant policies in Australia, moving to a different country as a doctoral candidate or early-career researcher must be an increasingly daunting prospect. Yet, policy-makers, funders, education researchers and research managers tell us that international collaboration, often manifest as researcher mobility amongst doctoral candidates and early-career researchers, is vital if we are to find creative solutions to the global challenges that the world faces right now on issues such as global warming, energy and food security.

The Hannover Recommendations $2019^{2}$ are the findings of a group of more than 160 experts from around the world, education researchers together with leaders of doctoral education, early career researchers and funding agency representatives, who met at an international conference in Hannover to discuss the topic 'Forces and forms in doctoral education worldwide'. In a defiant stance against the populist politics of recent years, these recommendations foreground inclusivity in doctoral education and mobility in a variety of forms. The first principle of the recommendations is "the establishment of a joint value system rooted in the universal principles of the United Nations human rights charter, based on respect for the individual, for the equilibrium of knowledges from south, north, east and west -

\footnotetext{
${ }^{1}$ The polling company YouGov, found that while respondents in France, the US and the UK were least likely to see globalisation as "a force for good", $>70 \%$ of respondents in East and Southeast Asia believed that it had been. https://yougov.co.uk/topics/politics/articles-reports/2016/11/17/international-survey. Both the Chinese president and the Indian prime minister have spoken out in support of globalisation at consecutive Davos meetings in 2017 and 2018.

${ }^{2}$ https://www.doctoral-education.info/documents.php [Accessed 19/11/19]
} 
including indigenous knowledges in an "ecology of knowledges". Fundamental to this ecology of knowledges is the ability for researchers at all levels to exchange ideas and to find, share and grow new knowledges. A necessary means of doing this - and a third principle in the recommendations - is a world-wide circulation of scholars to ensure a more balanced distribution of talent around the globe. Particularly at doctoral and early career researcher level it is noted that this community needs to acquire not only traditional academic research competencies and the breadth of professional skills but also the ability (and the opportunity) to work and function in multinational teams and multinational settings.

This reminds us of what Flores and Nerad (2012) refer to as a 'global village', which is needed to support the development of the next generation of researchers. Or, as the Hannover Recommendations put it, these skills and activities are necessary to develop the "original, responsible and ethical thinkers" (4) who can meet the complex challenges our world faces in the 21 st century. Researcher mobility is a key activity in realising Flores and Nerad's vision at the start of the decade and the objectives for improved doctoral education and a more inclusive and respectful research environment worldwide that is set out by the Hannover experts at the end.

We note that this particularly positive construct of the value to researchers and to research of a 'circulation of scholars' is distinct from other discourses that focus on the negative consequences of the unidirectional permanent flows of researchers from the Global South to the Global North, first explored as 'brain drain' in the seventies (Bhagwati \& Hamada, 1974; McCullock \& Yellen, 1977), following the Royal Society report that measured the exodus of British scientists to the USA and Canada (Royal Society, 1963). While the geopolitics of academic capitalism that privileges English and theoretical orientations from North America and Europe unquestionably persist, understandings of mobility have moved on to explore the complexity of types and timings of flow (Bekhradnia \& Sastry, 2005; Meyer, 2001; Universities UK, 2007). The picture of academic mobility summarised in the next section describes complex temporary flows of researchers around the globe as they progress through their career and new poles for doctoral training emerging outside of the North Atlantic nexus that has historically trained and retained many researchers from around the world.

\section{Academic mobility in numbers}

The numbers of researchers at all career stages who are internationally mobile are well documented. For instance, the Changing Academic Profession (CAP) Survey that was first administered in the early nineties and was followed up in 2007/2008 provided benchmark data from 19 countries $^{3}$ around the world. The survey reported from a completed effective sample of 800 at both 'junior' and 'senior'

\footnotetext{
${ }^{3}$ The countries participating in this research were Canada, the USA, Finland, Germany, Italy, the Netherlands, Norway, Portugal, the UK, Australia, Japan, Korea, Hong Kong, Argentina. Brazil, Mexico, South Africa, China and Malaysia.
} 
research positions. $38 \%$ of senior academic staff and $26 \%$ of their junior colleagues had spent at least a year in another country. (Teichler, Arimoto \& Cummings, 2013).

Sugimoto, Robinson-Garcia, Murray, Yegros-Yegros, Costas and Larivière (2017) more recently categorised global flows around the world of researchers across different career stages by analysing bibliometric data based on the records of 14 million papers from nearly 16 million individuals. The study focused on multiple affiliations in different countries by highly published researchers ${ }^{4}$ and therefore captured the most productive mobility activity. The authors found that 595000 researchers $(>4 \%)$ had at least two different international affiliations in that period.

Sugimoto et al. (2017) also highlighted patterns in mobility over the course of a research career. The authors characterised North America and Northern Europe as producers/cultivators of researchers who attracted many international doctoral and early-career researchers. Western Europe, Oceania, Southern Europe and sub-Saharan Africa were incubators where doctoral graduates from countries such as the USA and the UK moved to for postdoctoral positions; while Asia, Eastern Europe, North Africa and Latin America were recruiters of middle-career and more senior researchers.

At a national level, the effect in the UK of what Sugimoto terms global 'brain circulation' is that in the period 1996-2012, out of 266000 active UK researchers 72\% had published articles under a non-UK affiliation (i.e. had worked in that time for another research organisation outside of the UK) (Elsevier, 2013, cited in Guthrie, Lichten, Corbett \& Wooding, 2017.) ${ }^{5}$ Moreover, the composition of the academic community in the UK continues to internationalise. In 2007/2008, 38240 academic staff in the UK were non-UK nationals, representing $2 \%$ of the total UK academic population (HESA, 2009). In 2017/2018 this figure was 66 420, representing 31.3\% of UK academic staff (HESA, 2019).

South Africa has a much smaller percentage of international academics (Sehoole, Adeyemo, Phatlane \& Ojo, 2019), resting at $7-10 \%$ between 2000 and 2010. While sector-specific data is not currently available for academic migration, Kaplan and Höppli (2017) suggest a steady increase in the outflow of skilled workers from South Africa, predominantly contributing to the South African diaspora in the UK, Australia, New Zealand, Canada and the USA in the latter part of this decade.

However, at doctoral level, South Africa appears to play a regional 'producer/cultivator' role (Sugimoto et al., 2017:31) for the African continent. In 2016, 44\% of the 2916 doctoral graduates in South Africa were international compared to $19.6 \%$ of the total from the other SADC countries and $20.2 \%$ of the

\footnotetext{
${ }^{4}$ At least eight publications between 2008 and 2015

${ }^{5}$ For mobility survey findings across a range of countries, see Franzoni, Scellato and Stephan's (2012) review of findings from the 2009 GlobSci survey in the fields of biology, chemistry, materials, and earth and environmental sciences, across the following 16 countries: Australia, Belgium, Brazil, Canada, Denmark, France, Germany, India, Italy, Japan, the Netherlands, Spain, Sweden, Switzerland, the UK and the US.
} 
total from other African countries (EUA, 2018). This is similar in proportion to the UK, where the international PhD population has more than tripled from 1994/1995 to represent 47\% (46 345 doctoral researchers) in 2017/2018. ${ }^{6}$

The comparator data below (Fig. 8.1) have been compiled from a variety of national and international sources to provide further context for trends in international doctoral enrolments across a range of countries that produce large numbers of doctoral graduates in global terms. The data are shown within a nine-year window between 2008 and 2017 which accommodates the available data. It should be noted within this period there has also been an overall uplift in numbers of doctorate holders, growing by about $8 \%$ across OECD countries. Internationalisation of this growing doctoral community is visible across most countries except for the USA States and Germany which show a very small decline.

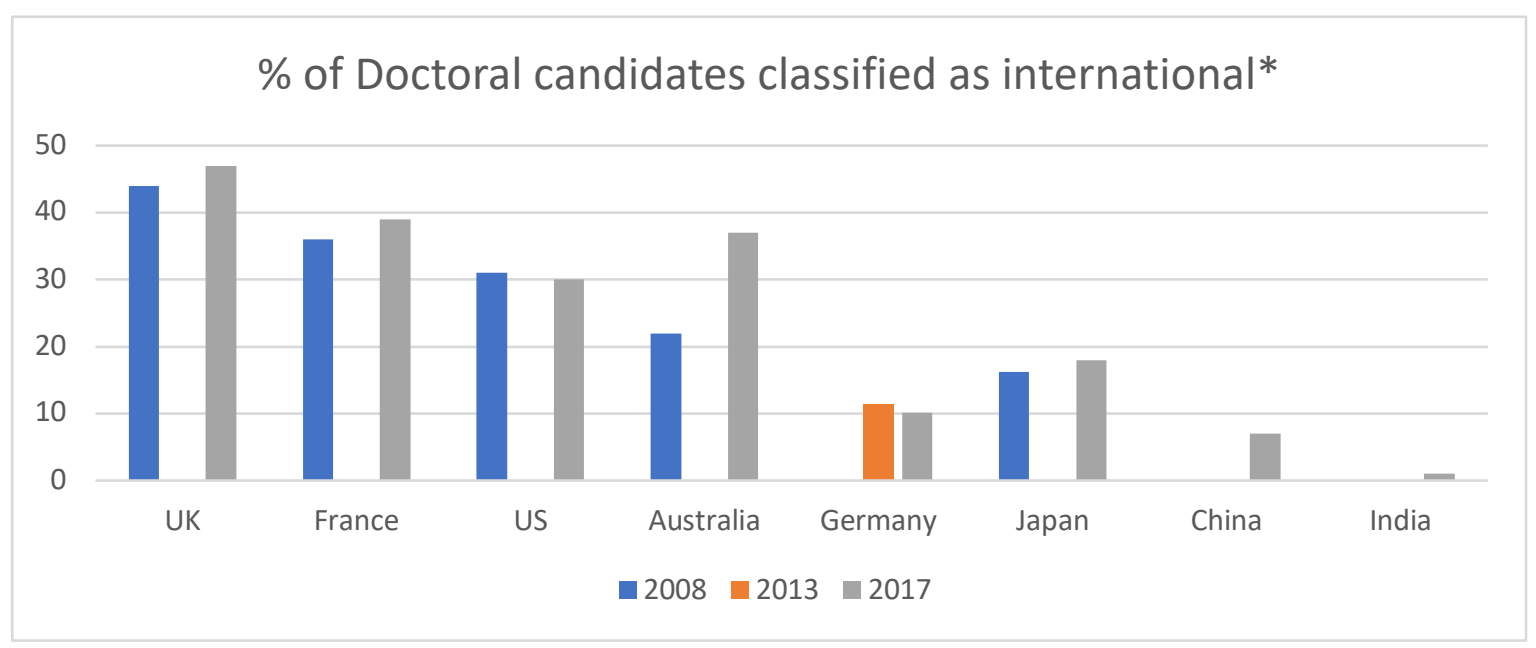

* 'International' is used here as an umbrella term to represent doctoral candidates termed 'international', 'temporary visa holders', 'foreign', 'non-UK domiciled' or 'Bildungsauslandaender' by the national data-holders.

\section{Figure 1: Percentage of doctoral candidates classified as international ${ }^{7}$}

\footnotetext{
${ }^{6}$ Data referenced in Fernández-Zubieta, Marinelli and Pérez (2013). 2013 and updated with HESA (2019)

7 Sources and definitions as follows: US - National Science Foundation, 2008 and 2017. 'Doctorates awarded' to 'Temporary visa holder'; France and Japan - Organisation for Economic Co-operation and Development (OECD), 2010 and 2019. 'International or foreign student enrolment as a percentage of total enrolment in tertiary education' at 'doctoral or equivalent'; UK - Higher Education Statistics agency. 'Postgraduate (research) non-UK domiciled'. Enrolled on a postgraduate research degree and measured in academic years 2007/2008 and 2017/2018; Australia - Australian Government Department of Education. 'International students' categorised as 'award course completions' for 'Doctorate by Research'; Germany - German Academic Exchange Service (Deutscher Akademischer Austauschdienst) 'Bildungsauslaender' enrolled on a PhD in the semesters within 2017 (across academic years); India - All India Survey on Higher Education 2017-2018. 'Foreign national students' enrolled on 'PhD and DPhil'; China - Ministry of Education the People's Republic of China. 'International enrolments as doctoral students'. Not including Hong Kong, Macau and Taiwan. Please note while the majority of national data-holders record enrolments, the data for the USA and Australia records awards.
} 
Despite the contemporary political turmoil and anti-immigrant sentiment of recent years it is clear that academic mobility is a key and growing feature of the global research system. The policy drivers for this will be summarised briefly in the next section.

\section{Policy context and 'imaginaries of mobility'}

Within the European Research Area (ERA) mobility is considered a so-called 'fifth freedom' (European Commission, 2007). It is one of the European Research Area's five priorities (Borrell-Damián, Morais $\&$ Smith, 2009), ensuring a circulation of skills and ideas around the world in a so-called global research system in which the best scientists follow the best science and the best resources. Academic mobility is linked in policy to the creation of better, more dynamic networks, improved scientific performance, improved knowledge and technology transfer, enhanced productivity, and ultimately better economic and social welfare.

This policy focus has produced a series of initiatives designed to facilitate doctoral and early-career researcher mobility both within and from outside ERA. In many European countries doctoral candidates are formally employed and consequently the policy interventions have included removing obstacles to cross-border mobility of researchers and movement between public and private research centres; targeting specific actions to support researchers' careers and to encourage transnational, inter-sectoral and interdisciplinary mobility; ${ }^{8}$ and creating joint infrastructure such as EURAXESS - a joint initiative of the European Commission and countries participating in the EU's Framework Programme for Research - which manages a network of over 500 service centres in 40 European countries, offering advice and information about the employment and other rights and obligations of researchers and employers in Europe.

Outside of the EU, there are numerous governmental funding programmes for international doctoral candidates that support doctoral mobility. Examples of these are the USA's prestigious Fulbright postgraduate scholarships programme that operates in more than 160 countries; the UK's Commonwealth, Newton and Saltire scholarships; and China's 'Outstanding Foreign Student Scholarships' that are offered both at both national and regional level.

In addition, there are many developing countries that offer scholarship programmes for academic staff in their universities to undertake $\mathrm{PhD}$ in a more developed research environment, for example the Indonesian government's '5000 Doktor' programme. The Malaysian government committed in its National Higher Education Strategic Plan Beyond 2020 to accelerating the production of doctorates to produce $100000 \mathrm{PhD}$ holders by 2020. These have included locally trained, overseas trained, and split-

\footnotetext{
${ }^{8}$ Marie Skłodowska-Curie actions are major research fellowship programmes that have been used by the European Union to support and encourage mobility across European countries.
} 
site programmes with universities from outside of the country. The split-site arrangement is gaining popularity in other countries such as the Philippines and Pakistan where a 'two plus three' model is emerging, with two years at the beginning of the doctorate in the home institution followed by three years spent in a developed research environment.

'Distributed' or 'diaspora' knowledge networks (Meyer \& Wattiaux, 2006; OECD, 2010) that have been established through previous doctoral or academic mobility are contributing to the establishment of new joint or dual programmes that usually require the doctoral researcher to spend at least one year in each university.

In South Africa, the Department of Higher Education and Training is working in partnership with other funders to support outgoing mobility for doctoral candidates on the New Generation of Academics Programme (nGAP).

The globalisation discourse, higher education league tables and metrics that privilege international coauthorship and citation numbers also drive policy and practice at an institutional level. Many universities offer fully funded scholarships for the best international candidates based on the perceived value of high-quality doctoral researchers to the research environment and the achievement of key metrics. At the very least, universities are investing funds in temporary placements, exchange programmes, research trips and extended training overseas.

What Dervin and Machart (2015:8) describe as the "imaginaries of mobility" have percolated through all levels of policy and practice without much investigation to date into the human experience of doctoral candidates. The next section moves on to explore exactly this amongst a group of 'mobile' doctoral researchers at three different kinds of UK universities.

\section{Definitions and methodology}

The research project uses interplay between emerging empirical data with multiple phases of literature review to better understand the experiences of mobile postgraduate researchers and to draw some conclusions about how the challenges they face might be mitigated and the positive impacts amplified. Ethical approval was sought and gained from Coventry University, UK.

Mobility was defined broadly as : (1) undertaking a doctorate outside of the researcher's main country of residence; (2) undertaking a doctorate by international dual or joint award, such as a cotutelle arrangement; and (3) spending more than one month based in a different research institution to the one where the researcher is registered for their doctorate. 
The project began with a preliminary review of academic and policy publications with a focus on academic mobility (including but not limited to doctoral candidates). This identified a number of areas for investigation that form the focus of the study. An online questionnaire was chosen as the method of data collection. The survey decision was based on economy, in terms of time and cost to the researcher and the respondents, and reach, in terms of number of institutions and individuals that could be targeted. Importantly it allowed for anonymity in responses.

The limitations of the chosen survey include social desirability response bias (Van de Mortel, 2008), lower response rates, the potential for over/under-representation of certain personality types (coverage bias) and the opportunity for respondents to misunderstand the questions posed. Some of these limitations were addressed through a variety of mitigations in the approach. These comprised: a pilot phase where the questionnaire was tested for ease of understanding and subsequently amended; the dissemination of the questionnaire via deans or directors of Graduate Schools or Doctoral Colleges (such that potential respondents would receive the link through a familiar name within their own institution); and the circulation of a number of reminders over a three-month period.

The questionnaire comprised a mixture of open and closed questions - balancing detail with a higher response rate (Fowler, 1993:69-93). It contained standardised questions which used a modified Likerttype scale. These responses provided a self-assessment of personal development in two keys areas that related to the mobility activity. The Researcher Development Framework (Vitae, 2011) was used as the basis for the self-assessment part of the questionnaire as it is used by the majority of UK universities and therefore offers familiar language and makes common understanding more likely. There were also questions with free text box responses. These provided data for a thematic analysis of narrative tropes relating to the respondents' personal experiences of mobility

Three UK higher education institutions were chosen to represent a range of types of university and geographical locations:

(1) Business-facing, South Coast, small doctoral population

(2) Research-intensive, North, large doctoral population

(3) Business-facing, Midlands, medium doctoral population

The link to the online questionnaire was circulated by deans or directors using newsletters and direct mail-outs. The questionnaire was initially open from 14 December 2018 until 28 February 2019, with a further extension of one month. A total of 2290 postgraduate researchers were targeted but only those who had undertaken mobility were invited to respond. There is no available data that show the size of the mobile subset. Altogether 44 responses were received, of which 40 were complete. Thirty-eight respondents disclosed their gender: 21 female/f/ 'feminine' and $17 \mathrm{male} / \mathrm{m}$. The respondents came from 
31 countries across the Global South and Global North. The majority of respondents were 26-45 years old (65\%). Forty per cent described their ethnicity as Black, Asian or Other; $5 \%$ declared a disability; $47.5 \%$ were single and without children. The breadth of the dataset in terms of ethnicity, gender, those with or without children does not necessarily align with the inequality of engagement in mobility noted in a number of academic papers referenced in the next section. Although the dataset is far too small to draw any conclusions about this, the broad cross-section of respondents did help to ensure that a variety of perspectives were included in the analysis on enablers and constraints.

The interpretation of the questionnaire results was shaped and influenced by further literature-based inquiry on migration, knowledge production and internationalisation of higher education.

\section{Academic mobility in the literature}

The next section provides a summary of the existing scholarly literature on academic mobility which is largely focused on research staff after completion of their doctorate. This literature has a strong focus on countries and continents where the research infrastructure is most developed. There is a lack of comparative studies between mobility across different disciplines. The considerations of equality of access to mobility opportunities are largely restricted to gender bias and do not extend to other 'protected characteristics', as defined by the UK Equality Act 2010, including disability, sexuality and race.

Like the policy discourse on academic mobility, much of the findings in the literature describe positive outcomes for mobility. The reality that for some, physical mobility provides access to equipment and technology that is not available in the home country or sending institution (Guth, 2008) is uncontested. Access to transnational networks that underpin international collaborations is another stated benefit (Woolley, Cañibano \& Tesch, 2016) although loss of networks and esteem in the home institution is also highlighted (Cruz-Castro \& Sanz-Menéndez, 2010; Gaughan \& Robin, 2004; Pezzoni, Sterzi \& Lissoni, 2012). De Filippo, Casado and Gomez (2009), Jöns (2011) and O’Hara (2009) point to enhanced productivity more generally and greater production of new knowledge specifically during a period of mobility, while Van Heeringen and Dijkwel (1987) suggest - based on empirical data of Dutch scientists - that mobility is a characteristic of productive scientists rather than a means to enhance productivity.

Inequality of engagement between genders (Leemann, 2010; Weert, 2013) and to some extent personality types (Ackers, 2005) is raised as a problem if mobility is linked to promotion opportunities.

More recently, Walakira and Wright (2018) have for the first time set out to capture the personal challenges to mobility in their exploration of feelings of homelessness in $\mathrm{PhD}$ fellows who were part of a Marie Curie International Training network in Europe, and the Integrative Graduate Education and 
Research Training programme in the USA. We might see this, at least to some extent, as part of a shift towards the more human-centred discourse on doctoral education that is embodied by the Hannover Recommendations and away from programme level analyses.

The literature review identified three areas for further investigation through the survey questionnaire. These represent areas where the existing literature was inconclusive or scant. They are: (1) the effect of mobility on career development; (2) the impact of mobility on knowledge development and production; and (3) equality and diversity in uptake of mobility schemes.

\section{Summary of survey findings}

This section gives an overview of the preliminary analysis of the survey results, looking in turn at the impact of mobility on the respondents' career development, their cognitive development and their perceptions of the barriers and enablers which, from their perspective, account for the developmental differences. The section concludes with a summary of the narrative tropes found in the questionnaire responses that related to respondents either seeking to pursue their doctoral education outside of their home country or prevented them from doing this.

\section{Confident, clear on values and the burden of starting over}

The questions related to career development focused on skills and attributes linked to 'professional and career development' (sub-domain B3 in the Researcher Development Framework). They are perceived awareness of career options, clarity of values, insight into how transition post-PhD might work, confidence to make the most of career opportunities, and the development of networks that might help to secure a job in future. Respondents were asked to rate their progress against what they might consider other doctoral candidates had achieved after a similar period of registration or what their understanding of their supervisor or supervisory team's expectations of them were at the point they completed the questionnaire.

Overall the respondents reported greater than expected development related to a personal understanding of their own values in terms of how these relate to and might influence their future career. They also indicated that their confidence to engage in other opportunities related to their career, including further international travel, had developed more quickly.

On the other hand, perceptions of networking skills were more mixed. Here between 15 and $25 \%$ of respondents reported experiencing slower than expected progress in the development of professional networks inside and outside the university, and the ability to use these networks to support next steps in their career, while between 12 and $23 \%$ of respondents conversely reported that they were more effective networkers in terms of scale and use, as a result of their international mobility. 
Their explanations of the developmental differences suggest that when programmes encourage networking activities and respondents have the confidence to exploit these opportunities, the sheer volume of new people that mobile postgraduate researchers can meet can mean that their networks rapidly expand. However, needing to "start from the ground up with a new institute" for some "stunts progress" and for others it can be very difficult to build networks outside of the main supervisory relationship.

\section{Creative ideation, language barriers and cultural accommodations}

Looking specifically at cognitive function and knowledge acquisition, the respondents were asked to consider how mobility had impacted their subject knowledge, critical thinking, research methods, and their ability to synthesise large amounts of information. Overall, respondents suggested a lag in research methods and information synthesis, where between 10 and $28.5 \%$ reported delayed development. However, 17.5 to $29.6 \%$ of respondents reported their development in these areas was faster than anticipated.

There was a general sense of faster development across the range of other knowledge and attribute areas with the most significant developmental advantage reported in the ability to contribute novel ideas and the confidence to take intellectual risk. For instance, $46.2 \%$ of respondents reported that confidence had developed quicker or significantly quicker than expected.

Respondents' explanations of the developmental differences include ideas of working harder in a new environment. They also valued having access to researchers from all over the world whom they could meet and share ideas with. However, language barriers - specifically "the gap between understanding of (the) subject and articulating it" - were perceived to have caused delays in development, along with a sense of exhaustion from negotiating cultural differences that meant there was less energy to spend on the research. One respondent commented as follows:

The energy lost in dealing with cultural translations be understanding my supervisor, the way in which immigrants are treated by immigration and institutions in general, and also in my personal life while making new friends took a toll on my physical and emotional health. For instance, the fact that I had to go through most of my research without being sure about what my supervisors meant, stunt the development of my critical thinking and academic writing skills taking a lot longer to develop than they could have taken.

Overall, the responses point to language proficiency and cross-cultural competencies (and the support to achieve that) as being key to enabling mobile postgraduates to maximise the benefits to cognitive development of a rich research environment with access to 'experts' and new thoughts and ideas. 


\section{Enablers and barriers to mobility}

Beyond the focus on developmental differences respondents were also asked to render free text responses to what they had found to be the key endogenous and exogenous enablers and constraints to doctoral mobility.

When considering their own personal character traits, respondents frequently used the narrative tropes of 'rising to the challenge' and thriving outside of their 'comfort zones'. Curiosity, courage and interest in meeting new people, seeing new places and interacting with 'experts' were strong personal enablers. Funding incentives such as government or university scholarships, or other types of financial support, including university fee waivers, employer funding, loans or gifts from the wider family were seen as external enablers. Emotional support from family, manager, 'advisor' or supervisor was seen as key along with practical support such as universities making mobility requirements flexible, additional funds for childcare and the need for a partner to 'do more'.

Barriers and constraints to mobility were related to the ability (or otherwise) to navigate 'bureaucracies' both external and internal to the university, such as banking, accommodation, visas and insurance, and negotiating ethics, getting access to library and a workspace. Overcoming time zones and communication lags both across supervisory teams such as in co-tutelle arrangements and with family and friends at home was noted as barrier to accessing timely support.

Difficulties in cross-cultural supervision were also noted by a number of respondents as aptly summarised by the following quotation:

Cultural shock in general and, in special, difficulty of understanding the feedback from my British supervisors. In Brazil, supervisors are more clear and assertive about their feedbacks, whereas UK supervisors tend to be more polite but also share less and give less support when giving feedback.

Finally, loneliness is reported as a major barrier to mobility with respondents expressing the challenges posed by the loss of social networks and the burden of 'building up everything from scratch'. 'Being an outsider' was also a strong motif with one respondent reporting a feeling of "prejudice with abroad people [...] even inside the University". A number of respondents described being left out due to language difficulties.

\section{Conclusion}

As academic mobility increases at all levels of seniority there is special responsibility to consider carefully its impact within the doctoral community. This is because doctoral candidates are the next generation of researchers. They are often newcomers in their own research communities of practice. 
Their major interactions with the host university can often be mediated mainly through a single supervisor or supervisory team and peer interaction and support might be infrequent. For many, the regulatory environment will focus on progression, rather than support, and their financial security through scholarships or loans depends on rapid development to meet pressing deadlines. Some, moving from Global South to Global North, feel they are under a lot of pressure to succeed on a prestigious scholarship programme. Others, undertaking North-South mobility, keenly feel the need to engage fully and equally with new colleagues in very different research environments in order to ensure mutual benefit and to acknowledge and show respect for their expertise.

Mobility at a doctoral level has clear advantages which are spelt out in policy and in parts of the academic literature. These advantages are also apparent from the conducted survey questionnaire responses. For instance, $84.6 \%$ of the respondents held that mobility had been beneficial to them. The findings highlighted increase in confidence, access to expertise, enhanced knowledge and understanding of self and others and development of problem-solving skills as positive outcomes. However, respondents also indicated the real personal, financial and systemic barriers that they face when undertaking mobility, which can create energy-sapping feelings of being an outsider.

To create the inclusive doctoral community set out in the Hannover Recommendations, we - the global village of supervisors, doctoral colleges or graduate schools and universities - perhaps need to rethink the imaginaries of mobility and to consider the needs of mobile postgraduate researchers. This will require us to look again at issues such as the timing of progression milestones and how flexibility might be built into the early phase of a doctorate, before upgrade, in programmes where candidates register in the first instance for an MPhil. Additional support and time to achieve early milestones would acknowledge the lag felt by some survey respondents in their ability to synthesise information while making cultural adaptations to their new context. The careful addition and balanced front-loading of additional taught elements across doctoral programmes could also offer easier opportunities for international candidates to build networks across the wider academic and professional services communities. Taught classes could also provide a stable, regular framework of formal and informal support in a familiar format for new doctoral researchers who are transitioning from a more structured master's programme. Further exploration of the benefits of pre-doctoral programmes could also be helpful. These programmes, which are currently piloted only by a small number of universities in the UK, might be delivered either remotely as pre-departure support in the candidates' home country or in the first few weeks of residence in the destination country. Such programmes might provide language support tailored for research purposes in the new context alongside an early opportunity to build peersupport networks which could ameliorate subsequent feelings of isolation and loneliness. Buddying programmes between cohorts and nationalities could also be explored as a way to provide informal 
emotional support as well as practical help in navigating bureaucracies related to banking, accommodation, visas and access to buildings alongside more formal university services.

Supervisors may benefit from peer-learning opportunities related to their own experiences of mobility or of working with international candidates. Focused training on intercultural supervision with time for open discussion and guided self-reflection may be helpful in supporting supervisors to share their challenges and to work together on ways to better support their doctoral researchers. Considerations of diversity when forming supervisory teams could assist with cross-cultural understanding and awareness in supervisory relationships. Peer observation, where appropriate, could afford supervisors the opportunity to broaden their own intercultural experiences and to observe and reflect on their own practice and of others.

Many of these measures to provide flexibility, to enhance support, and to improve networking and integration would be valuable for the entire doctoral community who - although perhaps not geographically mobile - may well be experiencing a period of transition, or of social or cultural mobility on their personal doctoral journey.

The voices of doctoral researchers from 30 countries - Global North and Global South - have provided fresh insights into how we might enable doctoral candidates to capitalise on their own mobility and encourage our respective institutions to maximise the benefits thereof for the rest of the academic community.

\section{References}

Ackers, L. 2005. Moving people and knowledge: Scientific mobility in the European Union. International Migration, 43:99-131.

Australian Government Department of Education, Skills and Employment. Higher Education Statistics [uCube multi-dimensional data structure]. Website:

http://highereducationstatistics.education.gov.au/FAQ.aspx

Bekhradnia, B. \& Sastry, T. 2005. Brain drain: Migration of academic staff to and from the UK. Oxford: Higher Education Policy Institute.

Bhagwati, J.N. \& Hamada, K. 1974. The brain drain, international integration of markets for professionals and unemployment: A theoretical analysis. Journal of Development Economics, 1(1):1942. 
Borrell-Damián, L., Morais, R. \& Smith, J. 2009. Collaborative doctoral education: Universityindustry partnerships for enhancing knowledge exchange. Brussels: European Universities Association.

Ministry of Education, The People's Republic of China. 2019. Statistical report on international students in China for 2018. Beijing: Ministry of Education.

http://en.moe.gov.cn/documents/reports/201904/t20190418_378692.html [Accessed 15 May 2020]

Cruz-Castro, L. \& Sanz-Menéndez, L. 2010. Mobility versus job stability: Assessing tenure and productivity. Research Policy, 39(1):27-38.

Deutscher Akademischer Austauschdienst. 2019. Wissenschaft Weltoffen 2019: Daten und Fakten zur Internationalität von Studium und Forschung in Deutschland. Bonn: Deutscher Akademischer Austauschdienst. http://www.wissenschaftweltoffen.de/publikation/wiwe_2019_verlinkt.pdf [Accessed 15 May 2020]

De Filippo, D., Casado, E. \& Gómez, I. 2009. Quantitative and qualitative approaches to the study of mobility and scientific performance: A case study of a Spanish university. Research Evaluation, 18(3):191-200.

Dervin, F. \& Machart, R. 2015. Introduction: Global academic mobility and migration - Between reality and fantasy. In: F. Dervin and R. Machart (eds). The new politics of global academic mobility and migration. Frankfurt: Peter Lang. 7-18.

EUA (European Universities Association). 2018. Doctoral education in South Africa: Ambitions and challenges. Brussels: European Universities Association.

European Commission. 2007. Strategic report on the renewed Lisbon strategy for growth and jobs: Launching the new cycle (2008-2010) - Keeping up the pace of change. Brussels: European Commission.

Fernández-Zubieta, A., Marinelli E. \& Pérez, S. 2013. What drives researchers' careers? The role of international mobility, gender and family. Sociología Y tecnociencia/Sociology and Technoscience, $3(3): 8-30$.

Flores, E. \& Nerad, M. 2012. Peers in doctoral education: Unrecognized partners. New Directions for Higher Education, 157 (Spring):73-83.

Fowler Jr, F. 2013. Survey research methods. Thousand Oaks: Sage. 
Franzoni, C., Scellato, G. \& Stephan, P. 2012. Foreign born scientists: Mobility patterns for sixteen countries. Cambridge MA: National Bureau of Economic Research.

Gaughan, M. \& Robin, S. 2004. National science training policy and early scientific careers in France and the United States. Research Policy, 33(4): 569-581.

Government of India, Ministry of Human Resource Development. 2018. All India Survey on Higher Education 2017-2018, New Delhi: Ministry of Human Resource Development.

Guth, J. 2008. The opening of borders and scientific mobility: The impact of EU enlargement on the movement of early career scientists. Higher Education in Europe, 33(4):395-410.

Guthrie, S., Lichten, C., Corbett, J. \& Wooding, S. 2017. International mobility of researchers A review of the literature. London: RAND.

HESA: See Higher Education Statistics Agency.

Higher Education Statistics Agency. 2009. Higher education statistics 2007-8. Cheltenham: HESA.

Higher Education Statistics Agency. 2011. Higher education statistics 2009-10. Cheltenham: HESA.

Higher Education Statistics Agency. 2019. Higher education statistics 2017-18. Cheltenham: HESA.

Jöns, H. 2011. Transnational academic mobility and gender. Globalisation, societies and education, 9(2):183-209.

Kaplan, D. \& Höppli, T. 2017. The South African brain drain: An empirical assessment. Development Southern Africa, 34(5): 497-514.

Leemann, R. 2010. Gender inequalities in transnational academic mobility and the ideal type of academic entrepreneur. Discourse: Studies in the Cultural Politics of Education, 31(5):605-625.

McCullock, R. \& Yellen, J.T. 1977. Factor mobility, regional development and the distribution of income. Journal of Political Economy, 85(1):79-96.

Meyer, J.B. 2001. Network approach versus brain drain: Lessons from the diaspora. International Migration, 39(5):91-110.

Meyer J. \& Wattiaux J. 2006. Diaspora knowledge networks: Vanishing doubts and increasing evidence. International Journal on Multicultural Societies, (1):4-24. 
National Science Foundation. 2008. Survey of Earned Doctorates. Alexandria: NSF.

National Science Foundation. 2017. Survey of Earned Doctorates. Alexandria: NSF.

O'Hara, S. 2009. Internationalizing the academy: The impact of scholar mobility: Higher education on the move. New developments in Global Mobility, 3: 29-47

OECD: See Organisation for Economic Co-operation and Development.

Organisation for Economic Co-operation and Development. 2010. Education at a glance 2008. Paris: OECD.

Organisation for Economic Co-operation and Development. 2010. Measuring innovation: A new perspective. Paris: OECD.

Organisation for Economic Co-operation and Development OECD. 2019. Education at a glance 2017. Paris: OECD.

Pezzoni, M., Sterzi, V. \& Lissoni, F. 2012. Career progress in centralized academic systems: Social capital and institutions in France and Italy. Research Policy, 41(4):704-719.

Royal Society, 1963. The emigration of scientists. London: Royal Society.

Sehoole, C., Adeyemo, K., Phatlane, R. \& Ojo, E. 2019. Academic mobility and the experiences of foreign staff at South African higher education institutions. South African Journal of Higher Education, 33(2):212-229.

Sugimoto, C., Robinson-Garcia, N., Murray, D., Yegros-Yegros, A., Costas, R. \& Larivière, V. 2017. Scientists have most impact when they're free to move. Nature:29-31.

Teichler, U., Arimoto, A. \& Cummings, W. 2013. The changing academic profession. Dordrecht: Springer.

Universities UK, 2007. Talent wars: The international market for academic staff. Policy Briefing, July.

Van de Mortel, T. 2008. Faking it: Social desirability response bias in self-report research. Australian Journal of Advanced Nursing, 25(4):40-48.

Van Heeringen, A. \& Dijkwel, P. 1987. The relationships between age, mobility and scientific productivity. Part I: Effect of mobility on productivity. Scientometrics, 11(5-6):267-280. 
Vitae, 2011. Researcher development framework. Cambridge: Vitae.

Walakira, L. \& Wright, S. 2018. 'I'm like a snail carrying my entire house with me': Doctoral fellows' experiences of a mobile life. Learning and Teaching, 11(2):51-68.

Weert, E. 2013. Support for continued data collection and analysis concerning mobility patterns and career paths of researchers. Brussels: European Commission.

Woolley, R., Cañibano, C. \& Tesch, J. 2016. A Functional Review of Literature on Research Careers. Brussels: European Commission. 